\title{
Massive Open Online Learning (MOOC) Benefits and Challenges: A Case Study in Jordanian Context
}

\section{Yousef Aljaraideh}

Assoc. Prof., in Educational Technology, Jerash University, Jerash, Jordan, yacob_yacob@yahoo.com

This study aims to identify the challenges and benefits of Massive Open Online Learning (MOOC) as perceived by the faculty members at Jerash University. A descriptive approach was used for collecting data. The sample of the study consists of (130) faculty members were chosen from all faculties at Jerash University. The findings have indicated that faculty members face several barriers when using MOOC. In addition, there is statistically significant difference between the genders on MOOC. The results also reveal that faculty members perceived MOOC as a great advantage for the users. Likewise, professors confirm that MOOC provides better learning opportunities than their counterparts. Finally, this study recommends all the higher learning education should introduce and implement MOOC for its numerous advantages.

Keywords: MOOC, benefits, challenges, online learning, case study, Jordan

\section{INTRODUCTION}

This study aims to investigate a new term that has a major contribution to the world wide education. The implementation of this term in education has always chief influence and progress on the learning process. It has a continuous progress, process and outcomes on its implementations. This educational term is 'Massive Open Online Learning' (MOOC) is considered as novel in the educational technology world. This type of learning encourages long life learning. In addition, students can learn anytime in anyplace, therefore, students can learn a lot of free online courses as the issue of MOOC has received considerable critical attention.

There are various definitions to the term MOOC, however, this term is explicated clearly by Jansen and Schuwer (2015). In Fact, a MOOC phenomenon was introduced in 2008 but it becomes well-known in 2012. They define it as "online courses designed for large numbers of participants, accessible by anyone anywhere as long as they have an internet connection, are open to everyone without entry qualifications, and offer a full/complete course experience online for free" (Jansen \& Schuwer, 2015).

Citation: Aljaraideh, Y. (2019). Massive Open Online Learning (MOOC) Benefits and Challenges: A Case Study in Jordanian Context. International Journal of Instruction, 12(4), 65-78. https://doi.org/10.29333/iji.2019.1245a 
There are several features and characteristics of MOOC. The main two types are widely used. The first one is (cMOOCs) which concentrate on the expanse of knowledge generation and the interaction via social media sites. The second type is (xMOOCs) like edX and Coursera. It is considered as the latest version of MOOCs which attempts to transfer university learning from traditional to online (Siemens \& Baker, 2012). Thus, both types of MOOC attract a huge number of students and instructors in higher education for its various benefits (Kim \& Chung, 2015).

In Relation, the MOOC becomes widely spread nowadays for countless reasons; openness for the public, no financial, geographical and cultural barriers, and improving the social domain through interaction between the students. MOOC has become an extension of e-learning in term of accessibility and flexibility.

There is a large volume of published studies describing the MOOC. Bonk, Lee, Reeves and Reynolds (2015) have described it positively: "MOOCs have their roots in two major developments. The first, towards open education, has become manifest through the open universities around the world. The second development, towards online education, came up with the use of new media and technologies". Besides, using MOOC always contributes to the promotion of modern learning strategies and keep universities up to date with the digital age. In this context, MOOC reinforces "education for all" concept - democratization of teaching- which means that student can access the courses with no charges (Belanger \& Thornton, 2013). Currently, sources of information are available in various forms and many forms of learning were emerged such as informal and formal learning. As a result of technological advances in the 21st century, MOOC is basically based on connectivism theory which tries to clarify the learning in technological and digital community (Siemens, 2005).

\section{Problem Statement}

Arab world countries are still in the preliminary stage when it comes to the implementation of MOOC. However, each country is in the stage of integrating and implementing MOOC in the education system at the level of higher education (Adham \& Lundqvist, 2015). In fact, MOOC is an important component in the climate system of education, and plays a key role in the process of learning. It offers a remarkable instructional opportunity for the students who are living in the third world countries. Besides, it is a suitable method for the students with low economic status and special needs (Welsh \& Dragusin, 2013). In relation to the developing countries, a number of researchers have sought to determine that MOOC has a potential to offer high-quality education. In fact, despite its development and efficacy, MOOC suffers from several major drawbacks: there are numerous barriers hindering the use of MOOC in Arab countries approximating the lack of computer skills, poor English language skills and inadequacy of infrastructure (Liyanagunawardena, Williams \& Adams, 2013). In Jordan, some universities such as Jerash University, as the scope of this study, began to activate MOOC courses for educational purposes. Consequently, this study tries to explore the actual and factual status of challenges and benefits of using MOOC at Jerash University from faculty member's point of views. This study positions the progressive process of a 
quantitative study conducted in Jerash University about the implementation of MOOC. Therefore, this study attempts to answer the following research questions:

1. What are the barriers faced by faculty members while using MOOC?

2. Are there any statistically significant differences in barriers faced by faculty members regarding to their gender and academic ranks variables?

3. What are the benefits that faculty members gain from using MOOC?

4. Do the faculty members' gender (x1) and academic rank (x2) have a significant effect on the benefits of MOOC (Y)?

\section{Significance of the Study}

This study makes a major contribution to research on MOOC by demonstrating a new concept of information and educational technology (ICT) domain; MOOC. This study provides a new insight to the entire process of learning and education via technology. In addition, the characterization of the MOOC is important for the learners' understanding on online learning. Besides, It also gives policymakers in private universities a clear picture about the real situation of using MOOC by faculty members and the barriers that prevent them from the ideal use of MOOC in education; the study is significant due to its need and chief necessity in helping the curriculum designers in incorporating MOOC in teaching and learning process. Furthermore, the usage of benefit can include both faculty members and students. In fact, this study aims to contribute to this growing area of research by exploring the MOOC with a great regard to help the faculty members to employ a new strategy and technique in their teaching. On the other hand, the students' computer and language skills get improved too. Finally, this study makes a major contribution to research on implementing MOOC by providing Jordanian libraries with current literature about challenges and benefits of MOOC at the level of higher education.

\section{LITERATURE REVIEW}

In this section, I shall elaborate with focus on the dependent variables (MOOC barriers and MOOC benefits) and independent variables (gender and academic rank of faculty members). The following takes them into considerations profoundly.

\section{MOOC Barriers}

MOOC is mainly used by students and instructors for academic purposes. And Educational institutions are also trying to integrate it in the teaching and learning process. However, there are some barriers which limit the optimal use of MOOC on higher education levels. Gulatee and Nilsook (2016) sum up those barriers are hindered by a computer illiteracy and English language skills, instant feedback and time consuming. Numerous studies also present the quality of MOOC and its validity in education (Rees, 2013; Lime et al., 2017). MOOC courses are also complicated because it needs a team of expertise in educational technology. Faculty members sometimes are not motivated due to lack of support and lack of incentive (Zheng et al., 2016). 
León-Urritia, Cobos and Dickens (2018) conducted a study on the impact of MOOC on higher education students. The sample of the study was randomly chosen from British and Spanish universities. Qualitative research was employed in this study. The results showed that students have a positive attitude toward incorporating MOOC in the higher education instruction. Despite the positive attitudes and concerns which is expressed by both of instructors and students toward MOOC, there are still several main barriers encounter the implementation of MOOC in the higher education level. The barrier is the assessment. For example: It is known that MOOC questions and assessment are chiefly relied on objective questions like; multiple choice, completion and matching. In contrast, MOOC does not give essay questions enough attention, which often measure higher-order thinking skills (Yuan \& Powell, 2013). Other barriers were identified by Bonk and Lee who pointed out certain issues such as consuming time, poor content quality and lack of support. These matters and other factors have decreased the MOOC usage (Bonk \& Lee, 2017).

The related literature to the developing countries revealed that most of MOOC's users are male, young and most of them are not well- educated. Thus, higher institutions in those countries should take in their consideration barriers of using MOOC such as gender gap, innovations literacy and users' previous knowledge to ensure successful and peaceful integration of MOOC for educational purposes (Christensen et al., 2013; Straumsheim, 2013).

The content of MOOC is English language which means the users should have the basic skills of English language in order to gain benefit from MOOC as well as to be able to interact with its content, as we know most of people in the developing countries have poor English language. Moreover, using MOOC needs basic computer skills, all previous studies which are conducted in the developing countries showed that users are not motivated to access into MOOC due to language and computer skills barriers (Adams, Liyanagunawardena, Rassool, \& Williams, 2013).

\section{MOOC Benefits}

One observer has already drawn attention to the benefit in MOOC. Gulatee and Nilsook (2016) indicated that MOOC has a distinctive feature meet students' expectation. Those features are: subject matter taught are freely offered, MOOC brings with its new teaching strategies, methods and technique like informal learning which could meet student' learning preferences. Well-designed MOOC by specialist, it can be as effective as a traditional lecture (Seimens, Gašević, \& Dawson, 2015). Compensation of experts, instant feedback, introducing new teaching strategies are other benefits were reported by (Griffiths et al., 2015).

Several attempts have been made to show the importance of the influence of MOOC on professional development of teachers and faculty members. Urrutia's study and Liu's study reported some results out of their research showing that MOOC improves teachers' language, ICT and teaching skills (Urrutia, 2016; Liu et al., 2014). Even students can gain great benefit from using MOOC. They become experts in the use of modern technology, and their computer and language skills improve gradually. Those students 
expressed their interest in taking another MOOC course in the future (Nigh, Pytash, Ferdig \& Merchant, 2015). In fact, this leads to confirm that previous teaching and computer experience considered as prominent signs in using MOOC curriculum in higher education. Recent evidence by Morris, Hotchkiss and Swinnerton (2015) suggests that previous educational experience is considered as a key factor that mainly affecting the use of MOOC. Another evidence by Haywood (2016) also stated that there is a significant relationship between learners' age and their intention to use MOOC whereas younger learner are more motivated to use MOOC than the older learner. Because they are able to deal with new technology from one hand. On the other hand, they are looking for new promotions in their fields.

Moreover, gender differences play a crucial role in using and integrating MOOC courses in public and particularly higher education. Shi and Cristea (2018) claim that Female learner are more enjoying and using MOOC than male learner. Besides, MOOC attracts older learners. In that case, it may indicate to their accustomed sufficient computer skills. MOOC has the ability to fill the gap in gender differences especially in developing countries. Chen, Yang \& Hsiao (2015) reported that the performance of female and male in flipped courses were equally.

\section{METHOD}

This study follows analytical descriptive approach throughout exploring the challenges and benefits of using MOOC in higher education as perceived by faculty members at Jerash University. Mean, standard deviation, and Two-way-ANOVA are used for the data analysis.

\section{Population and Sample of the Study}

The sample of the study is consisted of all faculty members in Jerash University at the academic year of 2018-2019. They are 180 faculty members from ten faculties according to admission and registration department. Statistically, they are also from different academic rank (assistant professor and below, associate professor and professor). They are asked about their perception towards challenges and benefits of using MOOC in higher education. The researcher distributed 180 questionnaires, missing and incomplete questionnaires were excluded. Thus, the number of valid questionnaires for analysis was 130. Table (1) below shows that the distribution of sample members according to gender and academic position.

Table 1

Distribution of Sample Members According to Gender and Academic Ranks

\begin{tabular}{llll}
\hline Variable & Categories & Frequencies & Percentage \\
\hline \multirow{2}{*}{ Gender } & Male & 75 & 57.7 \\
& Female & 55 & 42.3 \\
\hline \multirow{2}{*}{ Academic } & Assistant professor \& below & 73 & 56.2 \\
Ranks & Associate professor & 34 & 26.2 \\
& Professor & 23 & 17.7 \\
& Total & 130 & 100.0 \\
\hline
\end{tabular}




\section{Instrumentations}

The researcher has developed a questionnaire based on the previous study (Yuan \& Powell, 2013; Almuhanna, 2018; Lim et al., 2017). The questionnaire has three parts. First section enquired personal and demographic information such as academic rank and gender among faculty members. The second part consisted of (15) items that explore the benefits of using MOOC in higher education from faculty members' perception. The last part has (20) items that identify the barriers of using MOOC in higher education as perceived by faculty members. Five-point Likert scale (strongly disagree, disagree, neutral, agree, and strongly agree) is used to measure the challenges and benefits of using MOOC in higher education.

\section{Validity and Reliability of Instrument}

The validity of questionnaire was checked by faculty members in the faculties of educational sciences in the Jordanian Universities. They are experts in general curricula, educational technology and evaluation and assessment in order to express their opinion on the clarity of the language and technical drafting. Their views were taken into consideration. Four items were deleted, two items were added, and a number of items were modified. The final version of the questionnaire was introduced after the amendment to the committee of juries again, and they have confirmed that the questionnaire is suitable for the study purposes.

To ensure the reliability of questionnaire, the test-retest method was used by applying the scale and re-applying it after two weeks to a group (20 faculty members) from outside the study sample. Thus, the Pearson coefficient was calculated between their estimates at both times and it was (.88). Then, this value is appropriate for the purposes of this study.

\section{FINDINGS AND DISCUSSION}

Result related to the first question: What are the barriers faced by faculty members while using MOOC?

To answer the first question of the study, means and standard deviations of the barriers faced by faculty members when using MOOC were computed as presented in the table below.

Table 2

Means and Standard Deviations of Barriers Faced by Faculty Members while Using MOOC, Ranked in a Descending Order

\begin{tabular}{lllll}
\hline Rank & \multicolumn{1}{c}{$\mathrm{N}$} & Item & Mean & Std. Deviation \\
\hline 1 & 1 & Slow internet speed & 3.92 & .940 \\
2 & 19 & Nature of subject matter taught & 3.71 & 1.000 \\
3 & 2 & Poor Internet coverage & 3.69 & 1.055 \\
4 & 17 & Large number of students & 3.57 & 1.220 \\
5 & 18 & Insufficient institutional support & 3.56 & 1.194 \\
6 & 7 & Lack of sustainable funding & 3.55 & 1.012 \\
7 & 6 & Insufficient of infrastructure & 3.42 & 1.127 \\
8 & 12 & Quality of learning & 3.30 & .954 \\
9 & 9 & Lack of formal structures & 3.28 & .891 \\
10 & 13 & Effectiveness of learning & 3.28 & .889 \\
11 & 20 & Instructors' attitudes toward MOOC & 3.22 & .964
\end{tabular}




\begin{tabular}{lllll}
\hline Rank & $\mathrm{N}$ & Item & Mean & Std. Deviation \\
\hline 12 & 16 & High dropout rate & 3.19 & 1.182 \\
13 & 15 & The complexities of interacting with wider audiences & 3.15 & 1.201 \\
14 & 10 & MOOC involves a heavy workload & 3.10 & 1.048 \\
15 & 4 & Lack of English language skills & 2.99 & 1.273 \\
16 & 3 & Lack of Computer skills & 2.95 & 1.066 \\
17 & 11 & Lack of motivation & 2.89 & .982 \\
18 & 8 & Issues regarding plagiarism & 2.75 & 1.162 \\
19 & 5 & Lack of expertise & 2.65 & 1.127 \\
20 & 14 & Time consuming & 2.61 & 1.096 \\
\hline & Barriers & 3.24 & .599 \\
\hline
\end{tabular}

Table 2 shows that item 1 "slow internet speed" has the highest mean $(M=3.92, S D=$. 940), while item 14 "time consuming "ranked the least with a mean $(M=2.61, S D=$ 1.096). This table also shows that the barriers' mean as a whole is $(M=3.24, S D=.599)$. Those results could be interpreted as the faculty members have tried to incorporate MOOC in their teaching. However, it seems that they frequently faced certain barriers such as poor infrastructure, English and computer skills. The results of this question are consistent with previous studies (Gulatee \& Nilsook, 2016; Rees, 2013; Lime et al., 2017). When we compare the results of the current study with the results of previous studies such as Gulatee and Nilsook, (2016) we noticed that they reported that computer illiteracy and English language skills, instant feedback and time consuming are the major barriers of using MOOC. But in our study those barriers are not considered as the main issues that prevent academic staff from using MOOC. The differences in the barriers heavily depend on the nature of infrastructure, students, instructors and the mainstream culture with regard to the technology acceptance.

The weakness of implementation MOOC as perceived by academic staff is represented by poor infrastructure and lack of technical support. Thus, if Jerash University seeks to integrate MOOC as educational platform, they should upgrade and update the infrastructure and computers labs. While the strength point derived from the results of the first question is that using MOOC in the teaching and learning process does not consume time.

Results related to the second question: Are there any statistically significant differences in barriers faced by faculty members based on gender and academic rank?

To answer the second question of the study; means and standard deviations of the barriers faced by faculty members while using MOOC based on gender and academic rank were computed as presented in table 3.

Table 3

Means, Standard Deviations: Barriers Faced by Faculty Members when Using MOOC Based on Gender and Academic Rank

\begin{tabular}{lllll}
\hline Variables & Values & Mean & Std. Deviation & $\mathrm{N}$ \\
\hline Gender & Male & 3.18 & .604 & 75 \\
& Female & 3.32 & .587 & 55 \\
\hline Rank & Assistant professor or less & 3.13 & .631 & 73 \\
& Associate professor & 3.24 & .482 & 34 \\
& Full professor & 3.58 & .539 & 23 \\
\hline
\end{tabular}


Table 3 shows a slight variance between gender and academic rank as barriers faced by faculty members while using MOOC, Two-way ANOVA was conducted to find out whether there are statistically significant differences between the faculty members' gender and academic rank in reference to MOCC's barriers. The results are shown in table 4.

Table 4

Tow-way-ANOVA Results of Students' Responses based on Gender, and Academic Rank Variables

\begin{tabular}{llllll}
\hline Source & Sum of Squares & Df & Mean Square & F & Sig. \\
\hline Gender & 1.293 & 1 & 1.293 & 3.927 & .050 \\
Rank & 4.148 & 2 & 2.074 & 6.299 & .002 \\
Error & 41.484 & 126 & .329 & & \\
Corrected Total & 46.323 & 129 & & & \\
\hline
\end{tabular}

Table 4 shows that:

The results indicated statistically significant effect of academic members' gender on MOOC's barriers $\mathrm{F}=3.927, p \geq .05$. Since the significant value was equal to alpha value, it provides the evidence for the significant difference in academic members' gender and MOCC's barriers.

Those results indicate female professors encounter greater barriers than male professors while using MOOC. In current study male professors may have more free time than female professors, and this advantage helps them to expand the interaction with their students and provide them with instant feedback. However, female professors may not have sufficient time in utilizing MOOC due to cultural, institutional, and environmental circumstance.

The results also indicated a statistically significant effect of academic rank and MOCC's barriers $\mathrm{F}=6.299, p \geq .05$. Since the significant value was smaller than alpha, the result shows the significant effect of academic rank on MOCC's barriers. Due to academic rank variable, post hoc for multiple comparisons using LSD method was calculated as in table 5.

Table 5

Post Hoc Results for Multiple Comparisons Using LSD Method

\begin{tabular}{lllll}
\hline (I) rank & \multicolumn{1}{c}{$(\mathrm{J})$ rank } & Mean Difference (I-J) & Std. Error & Sig. \\
\hline Assis. professor or less & Associate professor & -.110 & .121 & .662 \\
& Full professor & $-.450(*)$ & .139 & .006 \\
\hline Associate professor & Full professor & -.341 & .157 & .098 \\
\hline
\end{tabular}

* The mean difference is significant at the .05 level.

The table shows groups benefited from the different teaching method. All groups have significant mean differences. As a rule of thumb, $\alpha \geq 0.05$ indicates a statistically significant difference between two means.

Multiple comparison test shows there are statistically significant differences at $(\alpha \geq$ 0.05 ) between assistant professor or less and full professor in favor of full professor. It 
might be a reason of keeping up with the technology development. Age gaps between full professors, assistant and associate professors could create computer literacy advancement differences. Older adult may not be able to cope with the rapid advance technology and thus are lacking the ICT skills which are a basic requirement for implementing MOOC strategy. Therefore, this finding could be concluded that age play a significant role in MOOC implementation. Younger professors are described as the digital generation; they are able to handle the barriers caused by utilizing MOOC in the teaching and learning process. The results of this study are consistent with the previous study (Haywood, 2016) which indicated that younger learner more motivated to use MOOC than the older learner. The strength point of the current result refers to that younger professors have less barriers comparing with older professors which means those professors are up to date with a new innovation. From the other side, the weakness point in the current result is that older professors are not highly motivated to use MOOC in their teaching process so that they encounter more barriers than younger professors.

\section{Results related to the third question:}

What are the benefits that faculty members gain from using MOOC?

To answer the third question of the study, means and standard deviations of the benefits that faculty members gain from using MOOC were computed as presented in tables 6 .

Table 6

Means and Standard Deviations of the Benefits that Faculty Members Gain from Using MOOC, Ranked in a Descending Order

\begin{tabular}{cclll}
\hline Rank & N & Item & Mean & Std. Deviation \\
\hline 1 & 9 & MOOC reinforced self-paced learning & 4.13 & 1.101 \\
2 & 10 & MOOC reinforced self-directed learning & 4.07 & 1.094 \\
3 & 4 & MOOCs are helpful for my professional development & 4.02 & .922 \\
4 & 1 & MOOCs provide learners access to Higher Education & 4.00 & .868 \\
5 & 5 & Using MOOCs in higher education can help students to & 3.97 & .769 \\
6 & 6 & MOmprove their level of education & 3.95 & .833 \\
7 & 3 & MOOC provide information and references which are & 3.92 & .874 \\
8 & 7 & useful for my academic researchers & & \\
9 & 2 & MOOCs are good starting point to prepare and design my & 3.75 & .808 \\
10 & 11 & MOOC facilitate learning for people with special needs. & 3.73 & 1.037 \\
11 & 8 & MOOC reducing cost of education & 3.72 & 1.012 \\
12 & 14 & MOOC offers high- quality education & 3.69 & 1.082 \\
13 & 13 & A platform for discussing teaching materials & 3.62 & 1.164 \\
14 & 12 & MOOC helps me to meet students' individual differences & 3.61 & 1.096 \\
& & Benefits & 3.82 & 1.018 \\
\hline
\end{tabular}

Table 6 shows that Item 9 "MOOC reinforced self-paced learning" receives the highest mean $(M=4.13, S D=1.101)$. Whereas item 12 "MOOC helps me to meet students' individual differences" ranked the last with a mean $(M=3.29, S D=1.018)$. This table also shows that the benefits mean of overall is $(M=3.82, S D=.699)$. The results showed that Jerash university's faculty members realized the greater benefits of MOOC. Based on the finding MOOC indeed, helps instructors attain course objectives, improve 
teaching climate, and increase students' learning motivation. Those results are consistent with previous studies (Gulatee \& Nilsook, 2016; Seimens, Gašević, \& Dawson, 2015). They reported that subject matter taught was freely offered, MOOC brings with it new teaching strategies, methods and technique like informal learning which could meet student learning preferences are the significant features and benefits of MOOC as educational platform. In the current study, MOOC reinforced both of self- paced and self- directed learning. Those features were reported as the most benefits of MOOC from academic staff views at Jerash University. The strength point of current result comparing with related literature review is that promotes the self- learning concept as well as reinforces the role of the students as the centre of the learning and teaching process. The weakness point in the current result is that the academic staff at Jerash University strongly belief that MOOC will not meet students' individual differences, although it is an important benefit and feature of MOOC in education domain.

Results related to the fourth question: Do the faculty members' gender (x1) and academic rank (x2) have a significant effect on the benefits of MOOC $(Y)$ ?

To answer the fourth question of the study means and standard deviations of the benefits that faculty members gain from using MOOC based on gender and teaching were computed as presented in tables 7 .

Table 7

Means, Standard Deviations of the Benefits that Faculty Members Gain from Using MOOC Due to Gender and Academic Rank

\begin{tabular}{lllll}
\hline Variables & Values & Mean & Std. Deviation & N \\
\hline Gender & Male & 3.81 & .809 & 75 \\
& Female & 3.84 & .519 & 55 \\
\hline Rank & Assistant professor or less & 3.65 & .719 & 73 \\
& Associate professor & 3.97 & .576 & 34 \\
& Full professor & 4.15 & .649 & 23 \\
\hline
\end{tabular}

Table 7 shows a slight variance in benefits that faculty members gain from using MOOC based on gender and academic rank variables. To find out whether there are statistically significant differences in these means, 2 ways ANOVA was conducted and the results are shown in table 8 .

Table 8

Two Way ANOVA Results of the Benefits that Faculty Members Gain from Using MOOC Due to Gender and Academic Rank

\begin{tabular}{llllll}
\hline Source & Sum of Squares & Df & Mean Square & F & Sig. \\
\hline Gender & .394 & 1 & .394 & .870 & .353 \\
Rank & 5.909 & 2 & 2.954 & 6.526 & .002 \\
Error & 57.037 & 126 & .453 & & \\
Corrected Total & 62.976 & 129 & & & \\
\hline
\end{tabular}

Table 8 shows that:

There are no statistically significant differences at $(\alpha \geq 0.05)$ based on gender variable. 
The results indicated no statistically significant effect of academic members' gender on MOOC's benefits $\mathrm{F}=.870, p \geq .05$. Since the significant value was bigger than alpha, it provides the evidence for the no significant difference in academic members' gender and MOCC's benefits.

This result may be interpreted as both female and male professors are aware of the importance of MOOC as a new learning style. They both realized that the role of ICT in facilitating teaching and learning process.

The results indicated statistically significant effect of academic rank on MOOC's benefits $F=6.526, p \geq .05$. Since the significant value was smaller than alpha, it provides the evidence for the significant difference in academic rank and MOCC's benefits.

There are statistically significant differences at $(\alpha \geq 0.05)$ due to academic rank variable, post hoc for multiple comparisons using LSD method was calculated as in table 9.

Table 9

Post Hoc Results for Multiple Comparisons Using LSD Method

\begin{tabular}{lllll}
\hline \multicolumn{1}{c}{$(\mathrm{I})$ rank } & $(\mathrm{J})$ rank & Mean Difference (I-J) & Std. Error & Sig. \\
\hline Assist. professor or less & Associate professor & -.325 & .140 & .071 \\
& Professor & $-.508(*)$ & .161 & .008 \\
\hline Associate professor & Professor & -.183 & .182 & .603 \\
\hline
\end{tabular}

* The mean difference is significant at the .05 level.

Table 9 shows there are statistically significant differences at $(\alpha \geq 0.05)$ between Assistant professor or less \& professor in favor professor. This result can be explained by the fact that although professors are less user of MOOC, but they are more convinced with MOOC than assistant and associate professors. Because of their long teaching experience, they are able to figure out the most effective and useful strategies for their students. The results of current study consisted with Morris, Hotchkiss and Swinnerton (2015) study, who suggested that previous educational experience is considered as a key factor that mainly affecting the use of MOOC. We conclude that professor prefer to integrate $\mathrm{MOOC}$ as educational tool. But the weakness point regarding obtained result is that assistant professors (younger user) did not expect the MOCC's benefits as professors do. Finally, the findings were based on faculty members' views. Moreover, most of academic staffs have never experienced the MOOC in their teaching. It is hoped that MOOC's experience generalizes among faculty members at Jerash University, which may improve the educational outcomes at the higher education institutions in Jordan.

\section{CONCLUSION}

To sum up the paper, a necessary reminder must be on the intense integrating of MOOC in the process of education has always chief influence and progress on the learning process. Therefore, the study takes this significance into considerations to finally come out with these results. Firstly, Jerash University Staff incorporate MOOC in their teaching, but there are definite barriers such as poor infrastructure, English and 
computer skills. Second, there is a slight difference between gender and academic rank as barriers faced by faculty members in using MOOC in which female professors encounter greater barriers than male professors. Third, the faculty members realized the greater benefits of MOOC in teaching process. However, there is a difference in gender regarding this point as both female and male professors are aware of the importance of MOOC as a new learning style. They both comprehended the significance role of ICT in abridging teaching and learning process. Finally, In the light of the findings the following suggestions were set:

1. Conducting a study on a wide range of respondents from various Jordanian universities.

2. Conducting a comparative study by comparing the usage of MOOC between developing countries

3. Employing qusai experimental approach to explore the effectiveness of MOOC in higher education institutions.

4. Activating the usage of MOOC by academic staff at Jordanian universities.

5. Adopting MOOC as educational tool by policymakers in the higher education institutions.

Curriculum designers should take in their consideration the current teaching strategies like MOOC.

\section{REFERENCES}

Adams, A., Liyanagunawardena, T., Rassool, N. \& Williams, S. (2013), Use of open educational resources in higher education. British J. of Educ. Tech., 44(5), 149-50.

Adham, R., \& Lundqvist, K. (2015). MOOCs as a method of distance education in the Arab world - A review paper. European Journal of Open, Distance and e-Learning, 18(1), 123-139. https://doi.org/10.1515/eurodl-2015-0009

Almuhanna, M. (2018). Participants' perceptions of MOOCs in Saudi Arabia (Unpublished doctoral dissertation). University of Sheffield, UK.

Belanger, Y., \& Thornton, J. (February 5, 2013). Bioelectricity: A quantitative approach. Duke University's First MOOC. Retrieved from https://dukespace.lib.duke.edu/dspace/bitstream/handle/10161/6216/Duke_Bioelectricit y_MOOC_Fall2012.pdf.

Bonk, C., \& Lee, M. (2017). Motivations, achievements, and challenges of self-directed informal learners in open educational environments and MOOCs. Journal of Learning for Development, 4(1), 36-57. http://j14d.org/index.php/ej14d/article/view/195.

Bonk, C., Lee, M., Reeves, T., \& Reynolds, T. (2015). MOOCs and open education around the world. England: Taylor \& Franci.

Chen, S.-C., Yang, S., \& Hsiao, C.-C. (2015). Exploring student perceptions, learning outcome and gender differences in a flipped mathematics course. British Journal of Educational Technology, 47(6), 1096-1112. https://doi.org/10.1111/bjet.12278. 
Christensen, G., Steinmetz, A., Alcorn, B., Bennett, A., Woods, D., \& Emanuel, E. J. (2013). The MOOC phenomenon: Who takes massive open online courses and why? Pennsylvania: University of Pennsylvania. http://dx.doi.org/10.2139/ssrn.2350964.

Griffiths, R., Mulhern, C., Spies, R., \& Chingos, M. (2015). Adopting MOOCs on campus: A collaborative effort to test MOOCs on campuses of the university system of Maryland. Online Learning, 19(2). https://eric.ed.gov/?id=EJ1062937.

Gulatee, Y., \& Nilsook, P. (2016). MOOC's barriers and enables. Intern. J. of Inform. and Education Technology, 6(10), 826-830. http:// doi.org/10.7763/IJIET.2016.V6.800.

Haywood, J. (2016) Learning from MOOCs: Lessons for the future. In E. De Corte, L. Engwall, \& U. Teichler (Eds.), From books to MOOCs? Emerging models of learning and teaching in higher education (pp.69-80). London: Portland Press.

Jansen. D., \& Schuwer, R., (2015). Institutional MOOC strategies in Europe: Status report based on a mapping survey conducted in October - December 2014. Retrieved from European Association of Distance Teaching Universities: http://eadtu.eu/documents/Publications/OEenM/Institutional_MOOC_strategi es_in_Europe.pdf.

Kim, P., \& Chung, C. (2015). Creating a temporary spontaneous mini-ecosystem through a MOOC. In C. J. Bonk, M. M. Lee, T. C. Reeves, \& T. H. Reynolds (Eds.), MOOCs and open education around the world (pp. 157-168). NY: Routledge.

León-Urritia, M., Cobos, R., \& Dickens, K. (2018). MOOCs and their Influence on Higher Education Institutions: Perspectives from the Insiders. J. of New Approaches in Educational Research, 7(1), 40-45. https://doi.org/10.7821/naer.2018.1.252.

Lim, V., Wee, L., Ng, S., \& Teo, J. (2017). Massive open and online courses (MOOCs) and open education resources (OER) in Singapore. arXiv preprint arXiv:1708.08743. Retrieved from https://arxiv.org/pdf/1708.08743.pdf.

Liu, C.-C. et al. (Eds.). (2014). Proceedings of the 22nd International Conference on Computers in Education. Japan: Asia-Pacific Society for Computers in Education.

Liyanagunawardena, T., Williams, S, \& Adams, A. (2013). The impact and reach of MOOCs: A developing countries' perspective. eLearning Papers, 33. Retrieved from http://centaur.reading.ac.uk/32452/.

Morris, N., Hotchkiss, S., \& Swinnerton, B. (2015). Can demographic information predict MOOC learner outcomes? Conference: EMOOCS 2015, At Mons, Belgium

Nigh, J., Pytash, K., Ferdig, R., \& Merchant, W. (2015). Investigating the potential of MOOCs in K-12 teaching and learning environments. J. of On. Lean. Res., 1(1), 85-106.

Rees, J. (2013). The MOOC rackets. Retrieved from http://www.slate.com/articles/technology/future_tense/2013/07/moocs_could_be_disastr ous_for_students. 
Siemens, G. (2005). Connectivism: A learning theory for the digital age. International Journal of Instructional Technology \& Distance Learning. http://citeseerx.ist.psu.edu/viewdoc/download?doi=10.1.1.87.3793\&rep=rep1\&type=pdf

Siemens, G., \& Baker, R.S.J.D. (2012). Learning analytics and educational data mining: towards communication and collaboration. In the Proceedings of the 2nd International Conference on Learning Analytics and Knowledge (pp. 252-254). ACM. https://doi.org/10.1145/2330601.2330661.

Seimens, G., Gašević, D., \& Dawson, S. (2015). Preparing for the digital university: A review of the history and current state of distance, blended and online learning. Retrieved from http:// linkresearchlab.org/PreparingDigitalUniversity.pdf.

Shi, L. \& Cristea, 1. (August, 2018). Demographic indicators influencing learning activities in MOOCs: Learning analytics of future learn courses. Paper Presented at the 27th International Conference on Information Systems Development, Lund, Sweden.

Straumsheim, C. (2013). Masculine open online courses. [Web log comment]. Retrieved from https://www.insidehighered.com/news/2013/09/03/more-female-professorsexperiment-moocs-men-stilldominate.

Urrutia, M. (2016). Professional development through MOOCs in higher education institutions: challenges and opportunities for Phd students working as mentors. Journal of Interactive Media in Education, 10(10), X, pp. https://doi.org/10.5334/jime.427.

Welsh, D., \& Dragusin, M. (2013). The new generation of massive open online courses (MOOCs) and entrepreneurship education. Small Business Institute Journal, 9(1), 5165. https://www.sbij.org/index.php/SBIJ/article/view/166/113.

Yuan, L., \& Powell, S. (2013). MOOCs and open education: Implications for higher education. Retrieved from http://publications.cetis.co.u/2013/667.

Zheng, S., Wisniewski, P., Rosson, M. B., \& Carroll, J. M. (2016). Ask the instructors: Motivations and challenges of teaching massive open online courses. In Proceedings of the 19th ACM Conference on Computer-Supported Cooperative Work \& Social Computing (pp. 206-221). New York, NY: Association for Computing Machinery (ACM). 